Research Article

\title{
Stenting of the esophagus in the course of the malignant dysphagia in elderly patients
}

Janusz Włodarczyk ${ }^{1, *}$, Alicja Włodarczyk ${ }^{2}$

1. Department of Thoracic and Surgical Oncology, Jagiellonian University Collegium Medicum, John Paul II Hospital, Cracow, Poland; E-Mail: jr.wlodarczyk@gmail.com

2. Faculty of Medicine Jagiellonian University Collegium Medicum, Cracow, Poland; E-Mail: alicjawlodarczyk9@gmail.com

* Correspondence: Janusz Włodarczyk; E-Mail: jr.wlodarczyk@gmail.com

Academic Editor: David G Smithard

Collection: Dysphagia in the Elderly

OBM Geriatrics

2021, volume 5, issue 2

doi:10.21926/obm.geriatr.2102171
Received: October 26, 2020

Accepted: May 05, 2021

Published: June 07, 2021

\begin{abstract}
Esophageal cancer is a disease with difficult clinical management, and palliative therapy is the only predominant treatment. This retrospective study analyses the results of clinical management of elderly patients ( $>75$ years of age) who were treated with esophageal stenting for malignant dysphagia due to primary esophageal cancer, including squamous cell carcinoma (SCC), esophageal adenocarcinoma (EAC), as well as secondary esophageal malignant strictures due to non-small cell lung cancer (NSCLC). Patients with esophagorespiratory fistula (ERF) were also included in the study. This study included 166 patients aged $75-88$ (mean age, 78 ) years. Nine $(5.4 \%)$ patients had upper malignant esophageal stenosis, $48(28.1 \%)$ had the middle, $43(25.9 \%)$ in the lower part of the esophagus, 49 (29.5\%) patients had EAC-related stenosis, and 17 (10.2\%) patients reported lung cancerrelated esophageal stenosis. Dysphagia was rated at 2.8 (range, $2-3$ ) before stenting and at 1.2 (range, 1-2) after the stenting procedure. Seven (4\%) patients experienced stenting
\end{abstract}

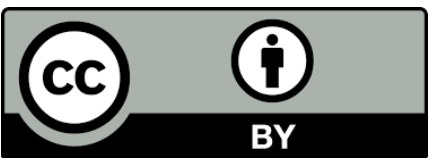

(C) 2021 by the author. This is an open access article distributed under the conditions of the Creative Commons by Attribution License, which permits unrestricted use, distribution, and reproduction in any medium or format, provided the original work is correctly cited. 
migration, 12 (7.2\%) had granulation tissue overgrowth and prosthesis obstruction, two (1.2\%) developed respiratory failure, and one $(0.6 \%)$ patient died. Twelve $(7.2 \%)$ patients were treated for ERF with double-stenting, and three (1.8\%) patients developed a secondary fistula after the stent implantation. The mean survival of patients with esophageal cancer and ERF was 101.8 days and 62.5 days, respectively. Esophageal stenting has proven a safe procedure in patients over 75 years of age. It has a low rate of stenting obstruction and migration. Patients with ERF are a particularly difficult group to treat, show very poor outcomes and short survival rates.

\section{Keywords}

Esophageal cancer; stenting; elderly; esophago-respiratory fistula; squamous cell carcinoma

\section{Introduction}

Squamous cell carcinoma (SCC) of the esophagus and adenocarcinoma of the gastroesophageal junction (EAC) are tumors of the upper gastrointestinal tract with a poor prognosis. Over the last three decades, the increase in the incidence of adenocarcinoma, considered an epidemic by some authors, is of particular concern. A steady rise in the number of new cases with SCC was observed [1-4]. Few studies showed that about $20 \%$ of patients underwent radical surgery and the remaining ones received palliative treatment only [1-5]. Primary esophageal cancer is the predominant cause of malignant dysphagia, but cancers such as lung cancer, thyroid cancer, or mediastinal cancer that secondarily infiltrate the esophagus may also be the cause. No precise data on the percentage accounting for secondary dysphagia are available in the medical literature $[2,5,6]$.

Esophageal stenting represents one of the most effective ways of managing malignant dysphagia because of the availability of technologically advanced stents, the variety of types, and the relatively simple techniques of implantation. Esophageal stenting, though a simple method of implantation, carries a risk of complications. In addition to stenting, endoscopic laser ablation techniques such as photodynamic therapy (PDT), chemotherapy, or interventional radiotherapy are also used in clinical management. Each procedure has its advantages that should be considered when considering patients with inoperable esophageal cancer for palliative treatment.

This study evaluates the treatment of malignant dysphagia, its safety, and the potentially lifethreatening complications after the treatment. It examines the full range of patient management, not only in terms of stenting but also in the management of esophago-respiratory fistula (ERF) and postoperative complications. Believably, this study may be a valuable contribution to the decisionmaking process of treatment of patients and illustrates how to follow the proposed recommendations.

\section{Patients and Methods}

This study presents a retrospective analysis of the results of clinical management of patients treated for malignant dysphagia in the Department of Thoracic Surgery, Jagiellonian University Medical College, Poland, between 2008 and 2018. 
Patients over 75 years of age disqualified from surgery for medically inoperable SCC, esophageal adenocarcinoma (EAC), or secondary dysphagia in the setting of inoperable lung cancer (NSCLC) underwent stenting. Patients with bronchoesophageal and esophagomediastinal fistulae were also included in the therapeutic management. Cancer staging was done on the criteria of Union for International Cancer Control (UICC) classification, 7th edition [7].

\section{Diagnostic Procedures}

Chest radiography/chest X-ray (CXR), chest computed tomography (CT), esophagoscopy, bronchoscopy, endobronchial ultrasound (EBUS), endoscopic ultrasound (EUS), abdominal ultrasonography, and positron emission tomography-computed tomography (PET-CT) were performed on patients qualified for the stenting. Patients with Karnofsky Performance Scale (KPS) $\leq 40$ were excluded from the stenting. The assessment of patient comfort after treatment was based on the KPS score [8].

Prior to planned treatment, dysphagia was classified according to a four-point scale, and bronchoscopy was routinely performed.

The degree of dysphagia was assessed based on a four-point scale [9]:

0-no dysphagia;

1-swallowing of a semi-liquid diet;

2-swallowing of a liquid diet;

3-dysphagia to the liquids and saliva.

The clinical status of patients with an ERF was evaluated, and the classification was based on our classification presented in a previous study [10].

Patients with dysphagia in the course of esophageal and lung cancer were routinely qualified for unilateral stenting, and the patients with ERF or bronchial tree compression were qualified for double or unilateral stenting.

\section{Esophageal Stenting}

\subsection{Patients with Malignant Stenosis without Fistula to the airway}

The esophageal prosthesis was performed under general anesthesia. Esophagoscopy was performed in order to localize the stenosis. If tumor-related stenosis was $<10 \mathrm{~mm}$ in diameter, dilations to $10 \mathrm{~mm}$ were performed using the rigid Savary-Giliarde bougie. After dilation, endoscopic evaluation, the length of tumor infiltration, and implantation of the prosthesis were performed under endoscopic guidance. A self-expanding partially covered stent (SEPCS) (Boston Scientific Corporation, Natick, MA, USA) was used for the stenting.

\subsection{Patients with Esophago-Respiratory Fistula}

Patients with ERF were evaluated based on the following classification [10]:

Type 1-Fistula to the mediastinum

Type 2- Fistula to the trachea

Type 3- Fistula to the bronchus

Type 4-Esophago-respiratory fistula after stenting 
The patencies of the bronchial tree and esophagus were assessed in patients with confirmed ERF. Patients with Type 2 and 3 fistulas qualified for the double-stenting.

The double-stenting procedure was performed under general anesthesia with a self-expanding partially covered stents (SEPCS) (Boston Scientific Corporation, Natick, MA, USA), a bifurcated Y stent (Demed, Mikolow, Poland), or with self-expanding covered bronchial stents (SECBS) and selfexpanding tracheal stents (SETS) (Boston Scientific Corporation, Natick, MA, USA) (Figure 1). Bronchial tree stenting was performed according to the previously described technique by Stephens [11].

A

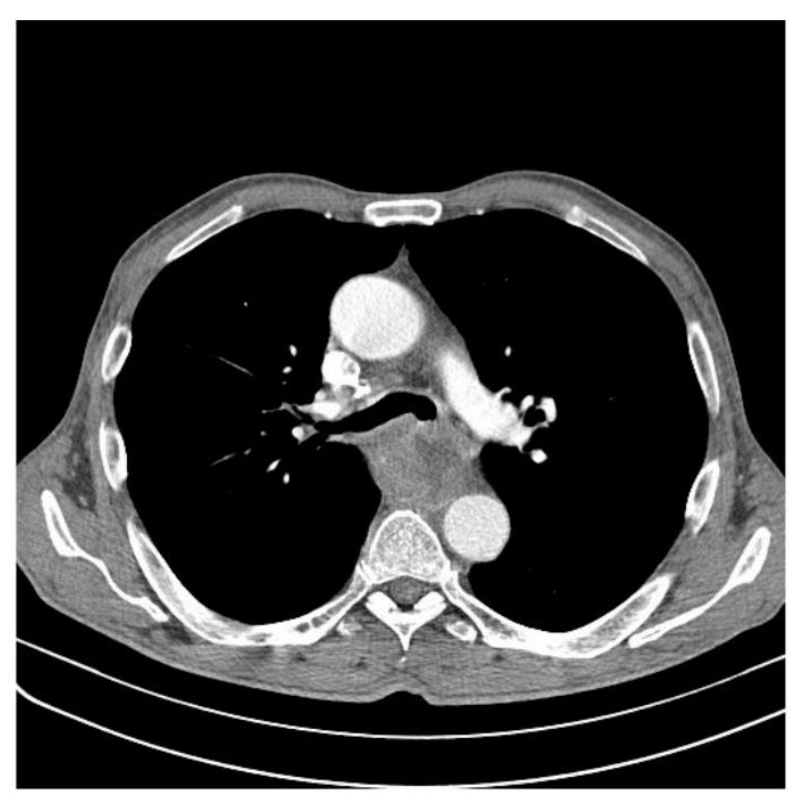

B

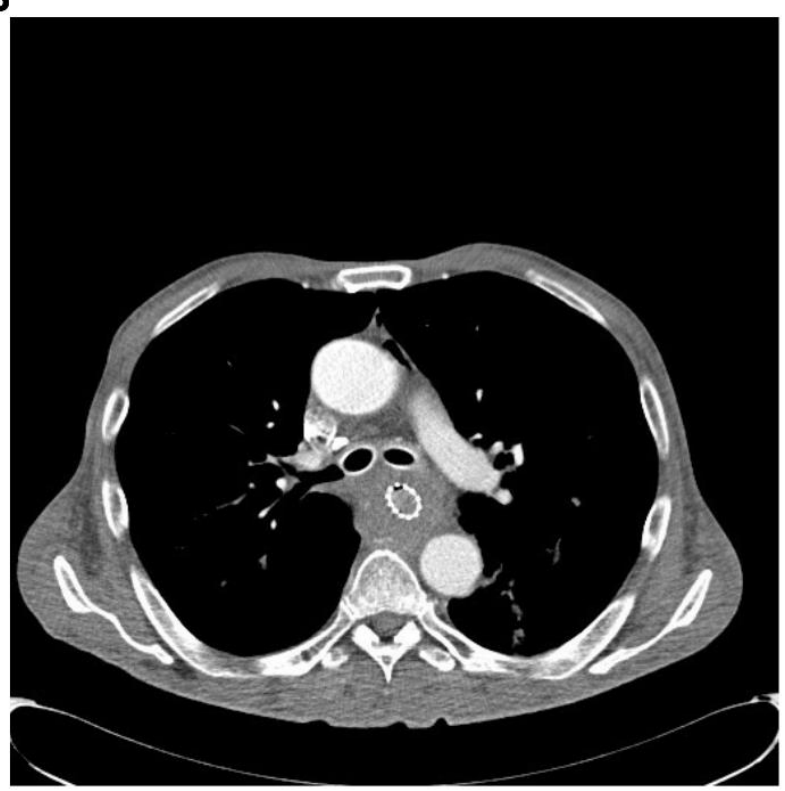

Figure $1 \mathrm{CT}$ scans showing advanced esophageal cancer with left bronchial stricture before $(1 \mathrm{~A})$ and after double-stenting (1B).

On postoperative day 1 , the patients underwent a chest radiograph and were given a liquid diet. Patients did not routinely undergo endoscopy of the esophagus and bronchial tree after doublestenting.

\subsection{Patients with Malignant Dysphagia in the Course of Lung Cancer}

Patients' diagnoses were performed as per the above-mentioned methods. Patients were qualified for esophageal stenting, and in the case of ERF or bronchial tree stenosis, for the doublestenting procedure.

\section{Postoperative Follow-up}

On postoperative day 1 , the patients were prescribed an oral diet, a chest radiograph was performed, and the degree of dysphagia after stenting was determined. On postoperative day 30 , dysphagia, general status, comfort status of the patients according to the KPC score were reassessed. Patients were monitored until death. 


\section{Statistical Analyses}

Statistical analyses were carried out using STATISTICA 10 PL software (StatSoft Inc., Tulsa, OK, USA). Differences between the causes of malignant dysphagia were assessed using GehanWilcoxon's, Kruskal-Wallis, Mann-Whitney, and chi-squared or Fisher's exact tests. Patients' survival rates were assessed using the Kaplan-Meier estimator. The Cox test was used to evaluate the risk factor in a group of patients undergoing chemo-radiotherapy after stenting. P-value $<0.05$ was considered statistically significant.

\section{Results}

The analysis included 166 patients aged 75-88 (mean 78) years.

\subsection{Patients with Malignant Stenosis without Fistula to the Airway}

In the study group, patients reported weight loss between 5 and $27 \mathrm{~kg}$ (mean $8.9 \mathrm{~kg}$ ), moderate dysphagia (mean 2.8, range 2-3), dyspnea, and cough in the group of patients with LC and ERF. The mean length of the esophageal cancer infiltration was $4.8 \mathrm{~cm}$ (range, 4-12 cm)

Table 1 shows the distribution of the esophageal stenosis.

Table 1 Study group - clinical and demographic characteristics.

\begin{tabular}{ll}
\hline Study population & Number of patients (no/\%) \\
\hline Sex (male/female) & $119 / 47$ \\
Mean age (range), years & $79(74-92)$ \\
Histopathology & \\
1. SCC & $100(60.2 \%)$ \\
2. EAC & $49(29.5 \%)$ \\
3. NSCLC & $17(1.0 \%)$ \\
Location of the esophageal stricture & \\
-upper esophagus & $9(5.4 \%)$ \\
-middle esophagus & $65(39.1 \%)$ \\
-lower esophagus & $43(25.9 \%)$ \\
-gastroesophageal junction & $49(29.5 \%)$ \\
Dysphagia score & \\
-grade 1 & 0 \\
-grade 2 & $142(85.5 \%)$ \\
-grade 3 & $24(14.4 \%)$ \\
Esophago-respiratory fistula (ERF) & $12(7.2 \%)$ \\
type 1 & $3(1.8 \%)$ \\
type 2 & $1(0.6 \%)$ \\
type 3 & $5(3.0 \%)$ \\
type 4 & $3(1.8 \%)$ \\
Treatment after stenting & $23(13.8 \%)$ \\
CTH & $8(4.8 \%)$ \\
RTH & $5(3.0 \%)$ \\
CTH/RTH & $10(6.0 \%)$ \\
\hline
\end{tabular}


Note: $\mathrm{CTH}$ - chemotherapy; RTH - radiotherapy; CTH/RTH - chemo-and radiotherapy; ERF - esophago-respiratory fistula; SCC - squamous cell carcinoma, EAC - esophageal adenocarcinoma, NSCLC - lung cancer. (ERF) esophago-respiratory fistula: type 1 (fistula to the mediastinum), type 2 (fistula to the trachea), type 3 (fistula to the bronchus), type 4 (fistula after stenting).

The breakup distribution of esophageal stenosis in the patients was as under:

1. In 9 (5.4\%) patients, the malignant stenosis was found between 18 and $25 \mathrm{~cm}$ from the incisors (in 5 (4.3\%) patients between 18 and $21 \mathrm{~cm}$ and in 4 (2.4\%) patients between 22 and 25 $\mathrm{cm})$. Stenting was performed in $2(1.2 \%)$ patients with fistula: one patient had Type 1 fistula, and one (0.5\%) patient had Type 2 fistula. The patient with Type 1 fistula underwent unilateral stenting, and the fistula was covered only on the esophageal side. The patient with Type 2 fistula underwent double, esophageal, and tracheal stenting, using a self-expanding tracheal stent (SETS).

2. In 48 (28.9\%) patients with SCC, esophageal stenosis was detected in the middle part of the esophagus. Out of them, 7 (4.5\%) patients with fistula, 2 (1.2\%) patients had Type 1 fistulas, and 5 (4.3\%) had Type 3). The patients with Type 1 fistula underwent unilateral esophageal stenting regaining full control over it, while patients with Type 3 fistula underwent double esophageal and bronchial tree stenting. Three patients underwent a Y-type prosthesis, and two underwent selfexpandable covered bronchial stent (SECBS).

3. Forty-three (25.9\%) patients underwent stenting of the lower third of the esophagus.

4. Forty-nine (29.51\%) patients underwent stenting due to EAC.

5. In $17(1.02 \%)$ stenting were performed due to esophageal stricture in the course of lung cancer (NSCLC).

\subsection{Stenting}

The esophageal stenting was performed in 164 (98.8\%) patients. In 2 (1.2\%) patients, due to complete tumor infiltration, restoration of the esophagus was unfeasible, and the stenting procedure was abandoned due to the risk of esophageal perforation. The patients were qualified for gastrostomy. Endoscopic examination revealed esophageal stenosis ranging in length between 4 and $12 \mathrm{~cm}$ (mean, $4.8 \mathrm{~cm}$ ).

\subsection{Dysphagia}

After the stenting, an improvement in swallowing was noted. Before stenting mean dysphagia score was 2.8 (range, 2-3) and after stenting 1.2 (range, 1-2) $(p=0.0001)$. In 31 (18.9\%) patients, the stenosis required dilation. Esophageal perforation occurred in two patients after dilation.

Patients' comfort level was assessed according to the KPC score. Before stenting, the mean comfort was rated at 56 (range, 45-70) and after stenting at 65 (range, 60-75)) $(p=0.0001$ ). 


\subsection{Complications following stenting}

\subsubsection{Complications Requiring Preventive Management}

Chest Pain: Among 89 (53.6\%) patients, chest pain occurred in 11 (6.6\%) patients who were treated with the upper esophageal stenting, in 21 (12.6\%) with middle esophageal stenting and 18 $(10.8 \%)$ with lower esophageal stenting. The pain was predominant in the group of patients who underwent upper esophageal stenting $(p=0.004)$. Mild painkillers were used in the treatment with resolution or clinical improvement. The pain was not an obstacle to oral nutrition.

Foreign Body Sensation: This complaint was reported in 38 (22.9\%) patients. Eleven (6.6\%) patients experienced the sensation in the proximal esophagus, $12(7.2 \%)$ in the middle esophagus, $8(4.8 \%)$ in the lower esophagus, and $7(4.2 \%)$ in the EAC. In $25(15.2 \%)$ patients with swallowing discomfort, the sensation was predominant in the proximal esophagus and ceased between 3 and 7 days after stenting $(p=0.0001)$.

Symptoms of Gastroesophageal Reflux Disease: This complaint was found in 60 (36.1\%) patients. They required pharmacological treatment with proton pump inhibitors. Patients' comfort level showed an improvement. Irregular heartburn occurred in $12(7.2 \%)$ patients.

7.4.2 Complications Requiring Clinical Intervention (Table 2)

Table 2 Interventional management after stenting.

\begin{tabular}{lllll}
\hline Complication after stenting & SCC & EAC & NSCLC & P-value \\
\hline Migration & $3(1.8 \%)$ & $3(1.8 \%)$ & $1(0.6 \%)$ & \\
partial - no re-stenting & $1(0.6 \%)$ & $1(0.6 \%)$ & & \\
complete - no re-stenting & 0 & 0 & 0 & $\mathrm{p}=0.9$ \\
complete - re-stenting & $3(1.8 \%)$ & $3(1.8 \%)$ & $1(1.4 \%)$ & \\
Restenosis & $6(3.6 \%)$ & $5(3.0 \%)$ & $1(0.6 \%)$ & \\
granulation & & & & \\
- proximal end of the stent & $3(1.8 \%)$ & $4(2.4 \%)$ & $1(0.6 \%)$ & $\mathrm{p}=0.8$ \\
granulation - distal end of the stent & $3(1.8)$ & $1(0.6 \%)$ & 0 & \\
malignant obstruction & 0 & 0 & 0 & \\
Perforation & $2(1.2 \%)$ & & & \\
respiratory failure & $2(1.2 \%)$ & & & \\
Death & $1(0.6 \%)$ & & & \\
\hline
\end{tabular}

Note: ERF - Esophago-respiratory fistula; SCC-squamous cell carcinoma; EACesophageal adenocarcinoma; NSCLC-lung cancer.

Hiccups: Hiccups occurred in $3(1.8 \%)$ patients. Two (1.2\%) patients underwent EAC stenting, and $1(0.6 \%)$ patient in the lower third esophagus. Hiccups probably resulted from the compression of the diaphragmatic branches and irritation of the phrenic nerve. Due to persistent complaints, the stents were removed; the patients required dilation and placement of percutaneous endoscopic gastrostomy (PEG). 
Upper Gastrointestinal Bleeding: Immediately after the stenting procedure, upper gastrointestinal bleeding was observed due to stenting-related damage in 4 (2.4\%) patients; of them, 2 (1.2\%) patients required transfusion of 2 units of blood.

Incomplete Expansion of the Stents: Six (3.6\%) patients had an incomplete expansion of stents that required repositioning between 1 and 2 days after surgery.

\subsubsection{Life-Threatening Complications}

Respiratory Failure: Symptoms of respiratory failure occurred in 2 (1.2\%) patients requiring artificial ventilation between the 2 nd and 4 th day, postoperatively. After decannulation, the patients breathed normally and were discharged to home on postoperative days 6 and 8 .

Esophageal Perforation and Perioperative Death: Esophageal perforation was reported in 2 (1.2\%) patients after dilation. The patients underwent stenting. Coverage of the perforation with the prosthesis was obtained. A contrast study was performed to verify the tightness of the esophagus. In 1 (0.6\%) patient, cardiac arrhythmia with cardiac arrest occurred. The patient died on postoperative day 7 . In the other patient, the postoperative course was satisfactory; hence, the patient was discharged on postoperative day 10.

\subsubsection{Endoscopic Re-Interventions}

Esophageal Stents Migration: Migration of the stents was found in 7 (4.1\%) patients: in $1(0.6 \%)$ with NSCLC, $3(1.8 \%)$ with SCC, and $3(1.8 \%)$ with EAC. There was no statistically significant difference between the esophageal cancer location and stents migration $(p=0.9)$. In 2 (1.2\%) patients, repositioning of the stent was performed, in $4(2.4 \%)$ patients, a re-stenting procedure was done, and in $1(0.6 \%)$ patient, the patency of the esophagus after stent removal was found satisfactory and required no re-stenting (Table 2 ). There was no correlation of stent migration with the age of patients $(p=0.4)$.

Obliteration of the Prosthesis (Recurrence of Dysphagia): Twelve (7.2\%) patients showed obliteration of the stents due to granulation tissue overgrowth (Table 2). No statistically significant difference was observed between the location of the implanted stents in the esophagus and the occurrence of obliteration ( $p=0.8$ ). In no patient, the neoplastic nature of the overgrowth was confirmed. The overgrowth of granulation tissue into the prosthesis was detected between 30 and 91 (mean 60) days after stenting was performed. Patients with an obstructed stent required either removal or re-stenting using the stent-to-stent approach in $8(4.8 \%)$ and 4 (2.4\%) patients, respectively. The esophageal stents obstruction and the patients' age showed no statistically significant correlation $(p=0.8)$.

Patients with Compression of the Airway after Esophageal Stenting: Of the patients who underwent esophageal stenting, bronchial tree stenosis developed in 12 (7.2\%), 4 (2.4\%) patients had left main bronchus stenosis, and $2(1.2 \%)$ had tracheal bifurcation. Three patients also required stenting during the same procedure, and one on the first postoperative day. Six (3.6\%) patients underwent additional stenting procedures by implanting a $Y$ prosthesis, while the 
remaining 6 (3.6\%) patients had non-critical bronchial tree stenosis of about 30\%. The patients were in good clinical condition and remained under observation.

\subsubsection{Patients with ERF}

Table 1 shows treatment of the ERF in 12 (7.2\%) patients. In 9 (5.4\%) patients, it was the primary form of fistula, and in $3(1.8 \%)$ patients, the secondary form was a complication developed after stenting. Seven (4.2\%) patients underwent double-stenting (esophagus and bronchial tree) and 2 (1.2\%) underwent esophageal re-stenting. The rate of dysphagia decreased from 2.84 to 1.2 ( $p=0.0001$ ) in all patients. Prior to stenting, the mean comfort based on KPS was rated at 51(range, 45-55) and after stenting at 62 (range, 50-65).

\subsubsection{Patients with Fistula to the Airway after Stenting}

In $3(1.8 \%)$ patients, fistula to the bronchial tree developed between 39 and 78 days after the primary esophageal stenting procedure. They underwent esophageal re-stenting with the use of self-expandable stents and silicone $Y$ stent. The mean survival of patients was 58 (range, 35-171) days.

\subsection{Adjuvant Therapy}

After stenting, 23 (13.8\%) patients qualified for adjuvant chemo-radiotherapy. This treatment had no impact on complications: esophageal prosthesis obstruction or migration $(p=0.8$ and $p=$ 0.9 , respectively) (Table 2 ).

\subsection{Survival}

In this study, the follow-up period ranged between 4 and 732 days. The mean survival time was 101.8 days (range, 4-732). Mean survival time in patients with SCC was 104.8 (range, 56-732) days with EAC 103.7 (range, 38-202) and with NSCLC 81.8 (range, 28-159) days (Figure 2). Mean survival in patients with ERF was 62.5 (range, 4-382) days. 


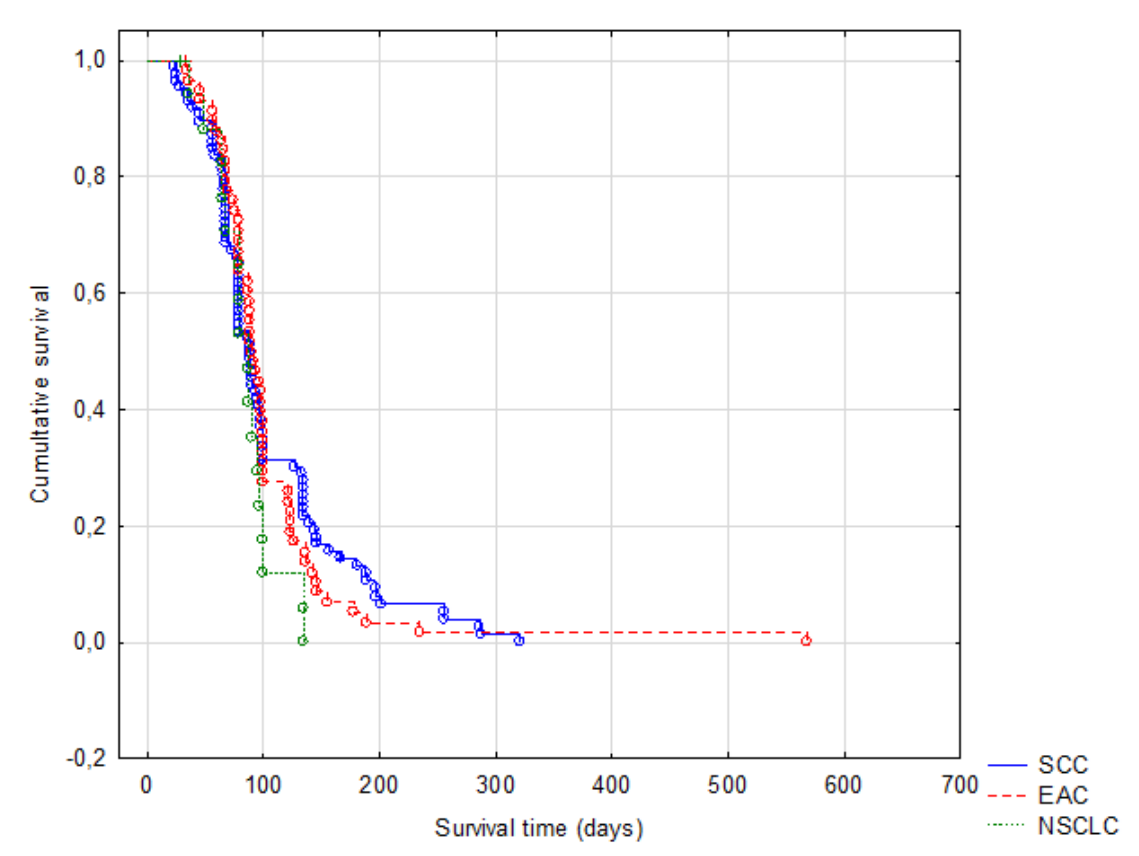

Figure 2 Survival curve of patients with esophageal carcinoma (SCC), adenocarcinoma of the esophago-gastric junction (EAC), and non-small cell lung cancer (NSCLC) $(p=$ $0.54)$.

\section{Discussion}

Owing to advancements in technology, clinical management is changing rapidly. Minimally invasive esophageal techniques are the standard of surgical management, and advanced endoscopic techniques are employed successfully for palliative treatment. The treatment of esophageal cancer poses a difficult clinical problem, and palliative treatment is the dominant method of management [2-5]. Stenting is one of the methods most commonly used in the palliative treatment of esophageal cancer $[12,13]$. Though a simple technique, some authors have reported a relatively high complication rate of stenting. Iwasaki et al. reported a mortality rate of $7.5 \%$ and post-treatment complications in approximately $50 \%$ of patients [12]. In some studies, the mortality rate ranged between 0 and 3\% [14-17]. In the current study, the complication rate equaled approximately $50 \%$, with a low mortality rate of $0.7 \%$.

Esophageal prosthesis obstruction, stent migration, and ERF are some of the potentially lifethreatening complications after stents implantation. Obstruction of the esophageal prosthesis may be temporary due to a dietary mistake, or permanent due to the granulation tissue overgrowth on the prosthesis poles (reported to range between 4-40\%)[14,15]. Typically, it can develop two to three months after prosthesis implantation. The reasons for stents obliteration remain poorly understood; however, the type of esophageal prosthesis, its construction, and composition may be responsible for stents obliteration. Several studies have shown that fully covered prostheses experience a lower rate of this complication (range, 3-18\%) [16-19]. A stent consists of a scaffold made of nickel-titanium alloy (nitinol), whose expanding forces can cause chronic injury to the esophageal wall. The second element is a polymer (prosthesis cover) that can destabilize after implantation and trigger a reaction between the stent and the esophageal mucosa. This is one of the reasons for the implant-host tissue reaction. 
After stenting, esophageal prosthesis migration is one of the major complications and ranges between 0 and $20 \%$ of cases [18-20]. Its risk depends on the type of stent used, location of the stenosis, and the use of adjuvant therapy [13]. It more often concerns with fully covered stents than partially covered stents. Verschuur et al. reported that migration of fully covered Ultraflex stents occurred in $17 \%$ of patients, whereas migration of fully covered Polyflex stents occurred in $29 \%$ of patients [20]. Rejim et al. analyzed the results of 997 patients in specific time intervals and showed the percentage at $11.4 \%[13]$. Eleven types of esophageal stents have been analyzed, and in our report the migration rate was $4.1 \%$, but we only used one type of stents, a partially covered prosthesis and this may determine our results and lower migration rates after stenting.

Several life-threatening complications include esophageal perforation and bleeding after prosthesis implantation. Esophageal perforation occurs during dilation of neoplastic esophageal stenosis, where it may be difficult or impossible to force through the neoplastic infiltrate. Usually, several studies have shown a low percentage of patients who experience this complication $[13,17$, $18,20]$. In the current study, perforation was found in 2 patients, and one patient died on postoperative day 7. Closure of the patient's perforation was verified by contrast examination after stenting. The patient was fed orally but developed cardiac arrhythmias and cardiac arrest on postoperative day 7. Dilation of neoplastic esophageal stenosis is always at risk of perforation, and the risk may be greater for elderly patients. Rejim et al. reported the percentage of patients requiring stenosis dilation to range between $2.3-17.5 \%$ [13]. The percentage of patients undergoing dilation in this study was also low, and this procedure was avoided before stenting as in other studies[13,20].

The exact cause of the bleeding remains poorly defined. Mechanical damage to the esophageal wall by the prosthesis may occur, but chronic exposure to the prosthesis might cause progressive ischemia, necrosis, and hemorrhage. In this study, these complications occurred perioperatively soon after prosthesis implantation in patients whose stenting was performed in the lower esophagus and the gastro-esophageal junction (GEJ). It is believed to be caused by anatomic and physiologic conditions of the esophagus, such as a well-vascularized area of the GEJ. GEJ is predisposed to the occurrence of both bleeding and perforation $[12,13,20]$. Few studies have reported bleeding rates of up to $8 \%[12,13]$.

ERF is one of the most difficult clinical problems in advanced esophageal cancer. It can occur as a primary complication or due to prior stenting. Its percentage ranges between 1 and 10\% [12, 13]. Treatment of patients is difficult and requires expertise and experience in clinical management. ERF occurrence indicates its double-stenting, which is the best way to control it. Both the European Society of Gastrointestinal Endoscopy (ESGE) and National Comprehensive Cancer Network (NCCN) guidelines recommend such double stenting [21, 22]. The treatment outcomes are poor, and patients may require repeated interventions. Bleeding, perforation, and fistula recurrence are the most commonly reported complications after double-stenting [21-25]. Perioperative mortality ranged between 0.5 and 7\%, and 30-day mortality ranged between 7 and $18 \%$ in few studies [26-29].

Other palliative treatments for esophageal cancer are brachytherapy, radiation therapy, endoscopic laser or photodynamic ablation therapy, and chemotherapy. Radiation therapy plays a vital role in effectively improving the nutritional comfort of patients. Lancelotta et al., in a metaanalysis, highlighted the safety and efficacy of radiotherapy over other modalities. Radiotherapy techniques are highly effective, leading to complete resolution of dysphagia in $87 \%$ of patients 
within one month, in two-thirds within three months, and in $50 \%$ of patients at six months after treatment [30]. Fuccio et al. showed the effectiveness of brachytherapy and considered it the most effective treatment for malignant dysphagia. Many authors have highlighted the effectiveness of combining methods such as stenting and radiotherapy or radio-chemotherapy [31]. Nonetheless, some authors have reported the occurrence of complications after concurrent use of chemo/radiotherapy and stenting, showing adverse effects of such a combined approach [13].

\section{Conclusion}

Overall, the current study conveys the clinical management of malignant dysphagia and its complications. The evaluation of patients over 75 years of age in this study seems to provide valuable guidance for the clinical management of this vulnerable population. The results of treatment in the current study support those in the literature and are characterized by a low rate of perioperative complications and safety of the stenting procedure.

\section{Author Contributions}

Conception JW, designe JW,AW, acquisition of data JW, AW interpretation of data JW, AW revision JW, AW, revised version JW. JW 70\%, AW 30\%

\section{Competing Interests}

Dr Włodarczyk J and Włodarczyk A have no conflicts of interest or financial ties to disclose.

\section{References}

1. Ferlay J, Shin HR, Bray F, Forman D, Mathers C, Parkin DM. Estimates of worldwide burden of cancer in 2008: GLOBOCAN 2008. Int J Cancer. 2010; 127: 2893-2917.

2. Cancer stat facts: Esophageal cancer [Internet]. NIH SEER. Available from: http://seer.cancer.gov/statfacts/html/esoph.html.

3. Tapias LF, Mathisen DJ, Wright CD, Wain JC, Gaissert HA, Muniappan A, et al. Outcomes with open and minimally invasive Ivor Lewis esophagectomy after neoadjuvant therapy. Ann Thorac Surg. 2016; 101: 1097-1103.

4. Rice TW, Patil DT, Blackstone EH. Esophagus and esophagogastric junction. In: AJCC Cancer Staging Manual. 8th ed. New York: Springer; 2017.

5. Sehdev A, Catencci DV. Gastroesophagal cancer: Focus on epidemiology, classification, and staging. Discov Med. 2013; 16: 103-111.

6. Madeya S, Borsch G. Upper intestinal endoscopy in 188 bronchial cancer patients and 118 breast cancer patients with abdominal symptoms. Med Klin. 1992; 87: 631-636.

7. Sobin LH, Gospodarowicz MK, Wittekind C. TNM classification of malignant tumours. 7th ed. New York: John Wiley \& Sons; 2011.

8. Karnofsky DA, Abelmann WH, Craver LF, Burchenal JH. The use of nitrogen mustards in the palliative treatment of cancer. With particular reference to bronchogenic carcinoma. Cancer. 1948; 1: 634-656. 
9. Blazeby JM, Williams MH, Brookes ST, Alderson D, Farndon JR. Quality of life measurement in patients with oesophageal cancer. Gut. 1995; 37: 505-508.

10. Włodarczyk J, Kużdżał J. Double stenting for malignant oesophago-respiratory fistula. Wideochir Inne Tech Maloinwazyjne. 2016; 11: 214-221.

11. Stephens KE, Wood DE. Bronchoscopic management of central airway obstruction. J Thorac Cardiovasc Surg. 2000; 119: 289-296.

12. Iwasaki H, Mizushima T, Suzuki Y, Fukusada S, Kachi K, Anbe K, et al. Factors that affect stentrelated complications in patients with malignant obstruction of the esophagus or gastric cardia. Gut Liver. 2017; 11: 47-54.

13. Reijm AN, Didden P, Schelling SJ, Siersema PD, Bruno MJ, Spaander MC. Self-expandable metal stent placement for malignant esophageal strictures - changes in clinical outcomes over time. Endoscopy. 2019; 51: 18-29.

14. Mayoral W, Fleischer D, Salcedo J, Roy P, Al-Kawas F, Benjamin S. Nonmalignant obstruction is a common problem with metal stents in the treatment of esophageal cancer. Gastrointest Endosc. 2000; 51; 556-559.

15. Homs MY, Steyerberg EW, Eijkenboom WM, Tilanus HW, Stalpers LJ, Bartelsman JF, et al. Single-dose brachytherapy versus metal stent placement for the palliation of dysfagia from esophageal cancer: Multicenter randomized trial. Lancet. 2004; 364: 1497-1504.

16. Conio M, Repici A, Battaglia G, De Pretis G, Ghezzo L, Bittinger M, et al. A randomized prospective comparison of self-expandable plastic stents and partially covered selfexpandable metal stents in the palliation of malignant esophageal dysphagia. Am J Gastroenterol. 2007; 102: 2667-2677.

17. Uitdehaag MJ, Siersema PD, Spaander MC, Vleggaar FP, Verschuur EM, Steyerberg EW, et al. A new fully covered stent with antimigration properties for the palliation of malignant dysphagia: A prospective cohort study. Gastrointest Endosc. 2010; 71: 600-605.

18. Vakil N, Morris Al, Marcon N, Segalin A, Peracchia A, Bethge N, et al. A prospective, randomized, controlled trial of covered expandable metal stents in the palliation of malignant esophageal obstruction at the gastroesophageal junction. Am J Gastroenterol. 2001; 96: 17911796.

19. Golder M, Tekkis PP, Kennedy C, Lath S, Toye R, Steger AC. Chest pain following esophageal stenting for malignant dysphagia. Clin Radiol. 2001; 56: 202-205.

20. Verschuur EM, Steyerberg EW, Kuipers EJ, Siersema PD. Effect of stent size on complications and recurrent dysphagia in patients with esophageal or gastric cardia cancer. Gastrointest Endosc. 2007; 65: 592-601.

21. Spaander MC, Baron TH, Siersema PD, Fuccio L, Schumacher B, Escorsell À, et al. Esophageal stenting for benign and malignant disease: European Society of Gastrointestinal Endoscopy (ESGE) clinical guideline. Endoscopy. 2016; 48: 939-948.

22. National Comprehensive Cancer Network Guidelines for the treatment of esophageal cancer 19. Available at: www.nccn.org/professionals/physcian-glsf-guidelines.asp\#site. 2019

NCCN Clinical Practice Guidelines in Oncology. Esophageal and Esophagogastric Junction Cancers, Version 2.2019. J Natl Compr Canc Netw.2019;17:855-883

23. Lopes CV, Pesenti Ch, Bories E, Caillol F, Giovannini M. Self-expandable metallic stents for palliative treatment of digestive cancer. J Clin Gastroenterol. 2008; 42: 991-996. 
24. Wilkes EA, Jackson LM, Cole AT, Freeman JG, Goddard AF. Insertion of expandable metallic stents in esophageal cancer without fluoroscopy in safe and effective: A 5-year experience. Gastrointest Endosc. 2007; 65: 923-929.

25. Verschuur EM, Homs MY, Steyerberg EW, Haringsma J, Wahab PJ, Kuipers EJ, et al. A new esophageal stent design (Niti-S stent) for the prevention of migration: A prospective study in 42 patients. Gastrointest Endosc. 2006; 63: 134-140.

26. Burstow M, Kelly T, Panchani S, Khan IM, Meek D, Memon B, et al. Outcome of palliative esophageal stenting for malignant dysphagia: A retrospective analysis. Dis Esophagus. 2009; 22: 519-525.

27. Ross WA, Alkassab F, Lynch PM, Ayers GD, Ajani J, Lee JH, et al. Evolving role of self-expanding metal stents in the treatment of malignant dysphagia and fistulas. Gastrointest Endosc. 2007; 65: 70-76.

28. Ohtsu A, Boku N, Muro K, Chin K, Muto M, Yoshida S, et al. Definitive chemoradiotherapy for T4 and/or M1 lymph node squamos cell carcinoma of the esophagus. J Clin Oncol. 1999; 17: 2915.

29. Touchefeu Y, Archambeaud I, Landi B, Lièvre A, Lepère $C$, Rougier $P$, et al. Chemotherapy versus self-expanding metal stent as primary treatment of severe dysphagia from unresectable esophageal or gastroesophageal junction cancer. Dig Liver Dis. 2014; 46: 283286.

30. Lancellotta V, Cellini F, Fionda B, De Sanctis V, Vidali C, Fusco V, et al. The role of palliative interventional radiotherapy (brachytherapy) in esophageal cancer: An AIRO (Italian Association of Radiotherapy and Clinical Oncology) systematic review focused on dysphagiafree survival. Brachyterapy. 2020; 19: 104-110.

31. Fuccio L, Scagliarini M, Frazzoni L, Battaglia G. Development of a prediction model of adverse events after stent placement for esophageal cancer. Gastrointest Endosc. 2016; 83: 746-752.

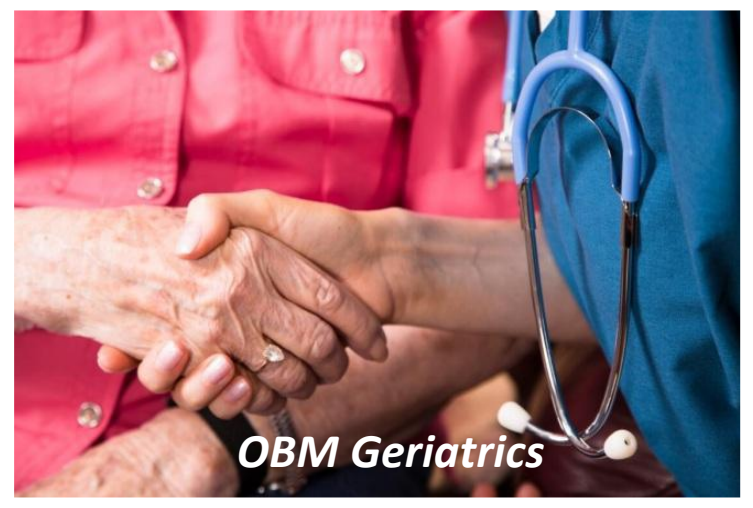

Enjoy OBM Geriatrics by:

1. Submitting a manuscript

2. Joining in volunteer reviewer bank

3. Joining Editorial Board

4. Guest editing a special issue

For more details, please visit: http://www.lidsen.com/journals/geriatrics 